\title{
Yearling proportion correlates with habitat structure in a boreal forest landbird community
}

\author{
Peter Pyle $^{\text {Corresp., } 1}$, Kenneth R Foster ${ }^{2}$, Christine M Godwin ${ }^{2}$, Danielle R Kaschube ${ }^{1}$, James F Saracco ${ }^{1}$ \\ ${ }^{1}$ The Institute for Bird Populations, Point Reyes Station, California, United States \\ 2 Owl Moon Environmental, Fort McMurray, Alberta, Canada \\ Corresponding Author: Peter Pyle \\ Email address: ppyle@birdpop.org
}

Landbird vital rates, such as productivity and adult survivorship, can be estimated by modeling mist-netting capture data. The proportion in which an adult breeding bird is one year of age (a "yearling"), however, has been studied only minimally in a few landbird species. Here we relate yearling proportion to habitat-structure covariates, including reclamation age, in a boreal forest landbird community. Data were collected at 35 constant-effort mist-netting stations over a six-year period, and consisted of 12,714 captures of adults, of 29 landbird species, including 4,943 captures of yearlings. Accuracy of age detemination (yearling or older) was assessed based on recapture data and error rates were estimated at a mean of $8.1 \%$ (range $0.0 \%$ to $19.4 \%$ ) among the 29 species, with 20 species showing age-error rates $<10 \%$. The estimated mean yearling proportion was 0.407 , ranging from 0.178 to 0.613 among species. Remote-sensed Enhanced Vegetation Index (EVI), a measure of habitat greenness, was positively correlated with age since reclamation up to 20 years, at which time it became comparable to that of natural stations. The probability of capturing a yearling for species associated with mature forest was lower at stations with higher EVI and the opposite was the case for species favoring successional habitats. These results suggest that yearling birds are being excluded from preferred breeding habitats by older birds through despotism and/or that yearlings are simply selecting poorer habitat due to lack of breeding experience or other factors. This dynamic appears to be operating in multiple species within this forest landbird community. Captured yearlings may also be "floaters," or non-breeding individuals not holding territories. However, presuming that yearlings show lower reproductive success whether floating or not, our results suggest that stations with high yearling proportions could be located within sink as opposed to source habitats. Overall, we infer that yearling proportion may become an important vital-rate measure of habitat quality and reclamation efforts, when combined with indices of population size, productivity, reproductive condition, and survivorship.

Peer) reviewing PDF | (2019:09:41351:1:1:NEW 31 Jan 2020) 
2 Yearling proportion correlates with habitat structure in a boreal forest

3 landbird community

Peter Pyle ${ }^{1}$, Kenneth R. Foster ${ }^{2}$, Christine M. Godwin², Danielle R. Kaschube ${ }^{1}$, and James F. Saracco ${ }^{1}$

1 The Institute for Bird Populations, Point Reyes Station, CA, United States of America

2 Owl Moon Environmental Inc., Fort MacMurray, Canada

Corresponding Author:

Peter Pyle 1

P.O. Box 1346, Point Reyes Station, CA, 94956 USA

Email address: ppyle@birdpop.org

\section{Abstract}

Landbird vital rates, such as productivity and adult survivorship, can be estimated by modeling mist-netting capture data. The proportion in which an adult breeding bird is one year of age (a "yearling"), however, has been studied only minimally in a few landbird species. Here we relate yearling proportion to habitat-structure covariates, including reclamation age, in a boreal forest landbird community. Data were collected at 35 constant-effort mist-netting stations over a sixyear period, and consisted of 12,714 captures of adults, of 29 landbird species, including 4,943 captures of yearlings. Accuracy of age detemination (yearling or older) was assessed based on recapture data and error rates were estimated at a mean of $8.1 \%$ (range $0.0 \%$ to $19.4 \%$ ) among the 29 species, with 20 species showing age-error rates $<10 \%$. The estimated mean yearling proportion was 0.407 , ranging from 0.178 to 0.613 among species. Remote-sensed Enhanced Vegetation Index (EVI), a measure of habitat greenness, was positively correlated with age since reclamation up to 20 years, at which time it became comparable to that of natural stations. The probability of capturing a yearling for species associated with mature forest was lower at stations with higher EVI and the opposite was the case for species favoring successional habitats. These results suggest that yearling birds are being excluded from preferred breeding habitats by older birds through despotism and/or that yearlings are simply selecting poorer habitat due to lack of breeding experience or other factors. This dynamic appears to be operating in multiple species within this forest landbird community. Captured yearlings may also be "floaters," or non-breeding individuals not holding territories. However, presuming that yearlings show lower reproductive success whether floating or not, our results suggest that stations with high yearling proportions could be located within sink as opposed to source habitats. Overall, we infer that yearling proportion may become an important vital-rate measure of habitat quality and reclamation efforts, when combined with indices of population size, productivity, reproductive condition, and survivorship. 
44

45

46

47

48

49

50

51

52

53

54

55

56

57

58

59

60

61

62

63

64

65

66

67

68

69

70

71

72

73

74

75

76

77

78

79

80

81

82

83

84

85

86

87

\section{Introduction}

Vital rates such as productivity and survivorship have increasingly been used to assess the status of landbird populations and inform conservation actions (DeSante, Nott \& O'Grady, 2001; Anders \& Marshall, 2005; Saracco, DeSante \& Kaschube, 2008; Robinson, Julliard \& Saracco, 2009; Rushing et al., 2015). While trends in landbird abundance are useful for highlighting species of conservation concern, the assessment of vital rates may help identify causes of declining trends; e.g., whether they are driven by factors on or away from breeding grounds (Newton, 2004; Albert, 2016). Data on vital rates collected at constant-effort landbird capture stations can also be used to predict population viability (Ryu et al., 2016) and can be modeled as functions of habitat variables to inform conservation-management strategies (DeSante,1995; Saracco et al., 2016; Saracco et al. 2018), including reclamation and restoration programs (Foster et al., 2017). To date, modeled vital-rate terms have primarily included those of productivity, often indexed as the probability that a captured bird at a station had fledged that year, and survivorship of breeding adults, as estimated from capture-mark-recapture models (Saracco, DeSante, \& Kaschube, 2009).

Population age structure within breeding populations of iteroparous species has received less attention but may reflect population dynamics and aspects of habitat quality (Rodenhouse, Sherry \& Holmes, 1997). In landbirds, advances in distinguishing yearlings from older adults for many species (Jenni \& Winkler, 1994; Pyle 1997) provide new opportunities to estimate proportions of first-year breeding adult landbirds in populations. Yearling proportions have been found to correlate negatively with landbird population densities (Graves, 1997; Sillett \& Holmes, 2005) and positively with marginal, lower-quality, or disturbed habitats, likely the result of competitive exclusion of yearlings by older birds from higher-quality breeding habitats (Graves, 1997; Holmes, Marra \& Sherry, 1996; Hunt, 1996; Bayne \& Hobson 2001; Háche \& Villard 2010). Yearling proportion has also correlated positively with reproductive success within a population the previous year (Sillet, Holmes \& Sherry, 2000), reflecting a direct demographic effect. Yearling proportions from capture stations have the potential to increase our understanding of landbird demography, habitat selection, and annual recruitment rates; however, assessments of yearling proportion thus far have been limited to a few directed studies on individual species in which one-year-old landbirds, in most cases males only, are readily distinguished from older birds in the field.

Here we examine yearling proportions using data from 18,799 captures of 12,714 individual landbirds, of 29 species (Table 1), captured at 35 Monitoring Avian Productivity and Survivorship (MAPS) constant-effort bird-capture stations over a six-year period in the oil sands region of northeastern Alberta (Fig. 1). The goals of this study were to (1) examine the accuracy and utility of yearling proportion as a measure of habitat structure in a boreal-forest landbird community, (2) assess the relationship between the probabilities of capturing a yearling and habitat based on multi-species hierarchical models, and (3) assess locally measured and remote-sensed structural vegetation changes in relation to habitat reclamation maturity (e.g., number of years since reclamation commenced) as it may affect species-specific and habitatspecific variation in yearling proportions. 
88

89

90

91

92

93

94

95

96

97

98

99

100

101

102

103

104

105

106

107

108

109

110

111

112

113

114

115

116

117

118

119

120

121

122

123

124

125

126

127

128

129

130

131

\section{Materials \& Methods}

\section{MAPS Stations}

We established 35 landbird-capture MAPS stations in the oilsands region of northeastern Alberta, Canada (Fig. 1), to monitor landbird demographics. Stations were located in landscapes that included both riparian and upland habitats (Foster et al., 2017). Six MAPS stations were operated in 2011, 24 stations were operated in 2012, and 30-35 stations were operated each year in 2013-2016; once a station was established it was operated in all following years, excepting a single station which did not operate in 2013 due to flooding, and five stations that were inaccessible in 2016 due to a regional wildfire. Stations were operated once every 10day period between 5 June and 7 August, for a total of six days of operation per station per year. On each day of operation, between eight and 14, fixed-location, 12-m mist-nets were operated for six hours, beginning at local sunrise. Captured landbirds were fitted with uniquely numbered leg bands. Birds were aged following Pyle (1997) as hatching year (HY) or older (after-hatching-year; AHY), and most AHYs were further determined to be either one-year-old yearlings (second-calendar-year; SY) or older (ASY) adults. Adults undetermined to SY or ASY were aged AHY. Prior to each season, biologists were extensively trained on criteria to distinguish SY and ASY individuals of captured species. Time permitting, digital images were obtained of the body plumage, wings, and tails of birds initially aged AHY that, following detailed examination of the images, resulted in age revisions to SY or ASY.

\section{Accuracy of age determinations}

Our analyses were based on 13,790 year-unique adult captures (different individuals captured in a given year), including 12,714 individuals of 29 species (Table 1). Of the total number of captures, 4,943 were aged as yearling adults (SY), 7,224 were aged as adults older than yearlings (ASY), and 1,623 were of adults that could not be precisely aged (AHY), indicating that $88.2 \%$ (range $57.9 \%$ for black-capped chickadee to $94.5 \%$ for magnolia warbler; see Table 1 for scientific names) of AHY birds were aged to SY or ASY. Other than black-capped chickadee $(57.9 \%$ aged) and ruby-crowned kinglet $(71.0 \%)$, we aged $>82 \%$ of AHYs to SY or ASY among the remaining 27 species (Table 1).

The ability to separate ASY from SY birds is critical to inferring yearling proportion, as errors may be biased toward either of these two age classifications, skewing results. Of 18,799 total adult captures (including within-season captures), 4,754 (25.3\%) were initially aged AHY and 3,131 of these $(65.9 \%)$ were re-determined to be SY or ASY through analysis of digital images from one or more captures. Many of the remaining AHY birds (Table 1) were either processed during times of high capture volume and were released without obtaining photographs, or were of early-molting species (e.g., black-capped chickadee) that had completed or nearly completed the prebasic molt and could not be aged to SY or ASY by the previous year's flight feathers (Pyle, 1997). The total number of AHY birds in the data set, 1,623 , represents $11.8 \%$ of our sample.

Recaptured birds were aged independently of previous age determination; thus, data on birds captured on multiple occasions allowed us to infer error rates. The mean percent of captures in which age was re-assessed (from SY to ASY or vice versa) according to verified 
132 recapture data was $8.1 \%$, ranging from $0.0 \%$ of 32 recaptured rose-breasted grosbeaks to $13319.4 \%$ of 93 recaptured yellow-rumped warblers (Table 1). Twenty of our 29 species showed 134 age-error rates $<10 \%$ (Table 1 ).

135

136

137

138

139

140

141

142

143

144

145

146

147

148

149

150

151

152

153

154

155

156

157

158

159

160

161

162

163

164

165

166

167

168

169

170

171

172

173

174

175

\section{Vegetation Data}

We collected in-situ, local habitat data on 1-5 broad habitat types at each station within 100m of each station's periphery (Foster et al., 2017). Habitat types were delineated based on plant community composition, vegetation structure, and hydrology. For each station and habitat type we estimated cover within three vegetation strata: 1$)$ understory cover $(0.5-5 \mathrm{~m}), 2)$ midstory canopy cover (5 -15 m), and 3) upperstory canopy cover (>15 m). Previously we have also assessed the proportions of each station that consisted of "natural," "disturbed," and "reclaimed" habitats, with the proportion of natural habitats (excluding open water) ranging from $0 \%$ to $98 \%$ (Foster et al., 2017). For the present analysis, 15 of the 35 stations, those with $>90 \%$ of the habitat undisturbed, were considered to be "natural" stations. For the five stations in which > $55 \%$ of the habitat was reclaimed ("reclaimed" stations), the age since reclamation, calculated as the difference between year of initial vegetation restoration (e.g., tree planting) and year of data collection, ranged from one to 34 years. The remaining 15 stations, which included natural vegetation cover of between $50 \%$ and $88 \%$, were classified as "disturbed" stations. To derive station-scale habitat metrics, we calculated weighted averages of each of these variables, with weights equal to the estimated proportion of each habitat type present at the station.

For remote-sensed habitat data we used 16-day, 0.25-km resolution, Enhanced Vegetation Index (EVI) data derived from the Moderate Resolution Imaging Spectroradiometer instrument of NASA's Terra satellite (MODIS product MOD13Q1; http://terra.nasa.gov/). We examined relationships between vegetation greenness and: a) in-situ habitat parameters, b) $\%$ natural cover, and c) probability of capturing a landbird yearling at each station. The EVI is a composite metric which incorporates structural and seasonal components of habitat quality including primary productivity (leaf chlorophyll content), leaf area, canopy cover, and vegetation complexity (Glenn et al., 2008), and which has previously been correlated with landbird occurrence and vital rates (Saracco et al., 2016). We extracted EVI cell values using the MODISSubsets function of the MODISTools package 30 (Tuck et al., 2014) in the statistical software package $R$ ( $R$ Core Team, 2015) at the $0.25 \times 0.25-\mathrm{km}$ scale for 81 cells surrounding each MAPS station, a grid extending $1.13 \mathrm{~km}$ in cardinal directions from station centers and a projected area $\left(5.11 \mathrm{~km}^{2}\right)$ estimated as being sampled by a MAPS station (DeSante \& Kashcube, 2009). For each station, we averaged values for the 81 cells across two June dates to obtain a single EVI value at each station for each year from 2000-2016 (2000 is the first year for which MODIS data are available).

\section{Data analysis}

To investigate habitat changes at reclaimed stations we created plots of cover percentages (for the three vegetation layers collected in situ) against years since reclamation at the five reclaimed stations and, for reference, the 15 natural stations. To provide insights into which vegetation layers contributed most strongly to variation in EVI, we plotted EVI values for the five reclaimed stations against years since reclamation for each year between 2000 and 2016 (a total of 85 data points). We also used a two-variable linear regression with year- and site- 
176

177

178

179

180

181

182

183

184

185

186

187

188

189

190

191

192

193

194

195

196

197

198

199

200

201

202

203

204

205

206

207

208

209

210

211

212

213

214

215

216

217

218

219

specific June EVI as the response variable and percent natural cover and years since reclamation as explanatory variables. We included both the five reclaimed stations and 15 disturbed stations in this analysis, considering un-reclaimed stations as being zero years since reclamation. The model was fit in $\mathrm{R}(R$ Core Team, 2015) and bivariate relationship plotted using the 'scatterplot3D' function in the R package scatterplot3D (Ligges \& Mächler, 2003). A quantile plot of standardized residuals and residuals $v$. fitted values plot suggested adequate model fit.

Our analyses of yearling proportion included 29 landbird species with a mean of $\geq 20$ individual adult (SY, ASY, and AHY) birds captured per year over the six-year period (Table 1). To investigate the relationship between yearling proportion and EVI we implemented a multispecies hierarchical model using data from all 29 target species. We assumed the age of year-unique individuals to be Bernoulli random variables with success probability $p_{i, j, k, t}$, whereby the $i, j, k$, and $t$ represent indices for individual, species, station, and year, respectively. Thus, $\mathrm{p}_{i, j, k, t}$ indicated the probability that a year-unique capture of an adult individual represented an SY bird. We modeled $\mathrm{p}_{i, j, k, t}$ with a logit-linear model:

$$
\operatorname{logit}\left(p_{i, j, k, t}\right)=a_{j[i]}+\beta_{j[i]} x \operatorname{evi}_{k, t}
$$

whereby $a_{j[i]}$ represented random species intercepts and $\beta_{j[i]}$ the species-specific regression coefficients for the relationship with the June $\mathrm{EVI}$ value at station $\mathrm{k}$ in year $\mathrm{t}$, evi $\mathrm{i}_{k, t}$. We modeled $a_{j[i]}$ and $\beta_{j[i]}$ as normally distributed with mean $\mu_{a}$ and $\mu_{\beta}$, and variances $\sigma_{a}$, and $\sigma_{\beta}$. We centered the continuous covariate, $\mathrm{evi}_{k, t}$ around zero prior to analysis to facilitate estimation. We implemented the model using Bayesian methods in JAGS (Plummer, 2003) from R ( $R$ Core Team, 2015) using the R package 'jagsUl' (Kellner, 2015). See Supplementary Information for details and model code. For this analysis, AHY individuals were included as unknown-age adults, and thus were estimated based on the model constraints and priors.

\section{Data availability and ethics statement}

Our study was conducted in accordance with North American Banding Council (https://www.nabanding.net/) and MAPS

(http://www.birdpop.org/docs/misc/MAPSManual18.pdf) protocols which minimize the impact of netting and processing on the health and safety of captured landbirds. All birds were captured and banded following protocols and permits issued by the Canadian Wildlife Service Bird Banding Office (Master Permit 10858) and the Alberta Government. The datasets generated and/or analyzed during the current study are available from the Harvard dataverse: https://doi.org/10.7910/DVN/NP2P2V.

\section{Results}

Extent of understory cover as measured in situ showed little relationship with station age since reclamation (Fig. 2a) whereas extent of midstory canopy cover increased with age since reclamation and was similar to midstory cover of natural stations by 30 years post reclamation (Fig. 2b). Extent of upperstory canopy cover among reclaimed stations also showed little relationship with station age up to 30 years, as compared to values derived from matured

Peer] reviewing PDF | (2019:09:41351:1:1:NEW 31 Jan 2020) 
220

221

222

223

224

225

226

227

228

229

230

231

232

233

234

235

236

237

238

239

240

241

242

243

244

245

246

247

248

249

250

251

252

253

254

255

256

257

258

259

260

261

262

natural stations (Fig. 2c). Remote-sensed, Enhanced Vegetation Index (EVI) values increased with years since reclamation, with the index equating to those of natural stations up to about 20 years since reclamation (Fig. 2d). When we compared values among the five reclaimed stations and the remaining 30 stations, the EVI index also correlated with both year since reclamation and proportion of a station's habitat considered natural (Fig. 3).

The mean yearling proportion of the 29 species over all six years and 35 stations combined was 0.407 , ranging from 0.178 in red-eyed vireo and northern waterthrush to 0.613 in swamp sparrow (Table 1). The probability of a captured adult being a yearling was negatively related to EVI (Fig. 4a), indicating that yearlings overall were found in less-forested habitats. This relationship was strongest for birds typical of forested habitats, as reflected by our capture data of adults, and weakest for species inhabiting earlier successional habitats (Fig. 4b-c). The probabilities of capturing yearlings for species preferring mature forests, such as magnolia warbler, cedar waxwing, northern waterthrush, and mourning warbler, were lower in those forested habitats and higher in successional habitats, whereas species preferring successional habitats, such as song sparrow, clay-colored sparrow, alder flycatcher, savannah sparrow, and chipping sparrow, had lower yearling probabilities in those habitats and higher probabilities in forested habitats (Figs. 4b and 5). We also found significant relationships between EVI coefficients, EVI mean, and EVI range among our 29 species, including a slightly positive correlation between EVI coefficient and range (Fig. 5), suggesting that more specialist species, those found in a narrower range of habitats, tended to have more negative correlations between $\mathrm{EVI}$ and yearling probabilities than species found in a wider range of habitats.

\section{Discussion}

Among our 35 stations, habitat-development patterns indicate that ground and understory cover do not change markedly after initial planting, that midstory cover develops within the first 30 years after initiation of reclamation, and that upperstory canopy does not noticeably develop until $>30$ years after initiation of reclamation activities. This is consistent with other studies on boreal-forest habitat succession, in which trees reach about $40 \%$ of their maximum height within 50 years and attain maximum height and canopy development (closure) at about 75 years of age (Bartels et al., 2016). EVI values will increase as midstory canopy develops within the first 20 years, but then may not change substantially as upperstory canopies mature and obscure the lower strata. It thus appears that EVI can track habitat characteristics, structure, and development for 20 - 30 years following vegetation planting, but that in-situ habitat data or data based on remote imagery that can distinguish canopy layers will be needed once upperstory canopy closure commences.

Mean yearling proportions among the 29 species examined show wide variation, from 0.178 in red-eyed vireo and northern waterthrush to 0.613 in swamp sparrow. We believe this variation reflects biological factors as opposed to age-determination or capture bias; following increased precision of age determinations though examination of digital images, mean error rate in age-determination was estimated at only $8.1 \%$, with 20 of our 29 species showing age-error rates $<10 \%$. The variation in mean yearling proportions may reflect factors related to speciesspecific variation in 1) the ability or proclivity to exclude yearling birds from higher quality

Peer) reviewing PDF | (2019:09:41351:1:1:NEW 31 Jan 2020) 
263 habitats by adults, 2) age-specific variation in capture probabilities, and/or 3) habitat variables

264

265

266

267

268

269

270

271

272

273

274

275

276

277

278

279

280

281

282

283

284

285

286

287

288

289

290

291

292

293

294

295

296

297

298

299

300

301

302

303

304

305

306 among our 35 MAPS stations.

Despite this variation in yearling proportions, forest-dwelling landbird species (cf. Rodewald 2015), those captured at higher rates in forested stations of our study, showed lower probabilities of yearling capture in stations with higher EVI, whereas species captured more frequently in successional breeding habitats showed higher capture probabilities of yearlings in forested habitats. Both of these results are consistent with hypotheses suggesting that yearling birds are excluded through despotism to suboptimal breeding habitats (Holmes, Marra \& Sherry, 1996; Bayne \& Hobson, 2001; Rohwer, 2004; Háche \& Villard, 2010). Alternatively, yearlings may also be selecting poorer habitats due to lack of breeding experience or other factors. In either case, it is possible that stations with high yearling proportions may occur in sink as opposed to source habitats (Pulliam, 1988; Donovan et al., 1995; Faaborg et al., 2010), presuming that yearling landbirds also average poorer reproductive success than older birds (Holmes, Marra \& Sherry, 1996). Our study also indicates that despotic exclusion or other factors affecting yearling dynamics may operate selectively and specifically among different species within a forest landbird community. Maintenance of high yearling proportions in suboptimal habitats for the species may promote emigration of yearlings to more suitable habitats for their second year of breeding (Greenwood \& Harvey, 1982; Rohwer, 2004), underscoring the need to model population age structure and habitat dynamics at the metapopulation level over multiple years (Faaborg et al. 2010).

Using capture data from the same study areas reported on here, Foster et al. (2017) found significant correlations between habitat covariates and captures of adult birds, young (HY) birds, and/or the probability of capturing a young bird (productivity). They also found that positive responses to reclamation age from obligate forest-dwelling species took more years to become evident than those for species preferring early successional-stage habitats. Our analyses further support relationships between demographic variables and habitat structure, including those related to habitat succession, suggesting that recruitment into the breeding population by yearling landbirds could be an initial indication of successful boreal-forest reclamation. We infer that yearling proportion can become an important vital-rate measure of both species-specific habitat suitability and the progress of reclamation efforts.

Captured yearlings may be "floaters," or non-breeding individuals not holding territories that are simply passing through the territories of breeding individuals (Sherry \& Holmes, 1989; Barber \& Robertson, 1999; Bayne \& Hobson, 2001). Demographic analyses using capture data, for example those examining correlations of yearling proportion with population density or productivity (Graves, 1997; Sillett, Holmes \& Sherry, 2000; Bayne \& Hobson, 2001; Rohwer, 2004; Háche \& Villard, 2010), should account for the possible presence of floaters. We suggest that breeding condition data, e.g., the extent of brood-patch or cloacal-protuberance development (Pyle, 1997) or recapture data confirming length of stay, may be useful in assessing the occurrence of yearling and older floaters in capture data sets (Barber \& Robertson, 1999). Habitat selection processes by age may also be subject to interannual or density-dependent effects (Rodenhouse, Sherry \& Holmes, 1997). By incorporating all demographic and breeding-condition variables in population models, that in turn include multiple species and multiple years of data, we suggest that yearling proportion may eventually be useful in estimating first-year recruitment and survivorship, the latter widely considered to be much 
307

308

309

310

311

312

\section{3}

314

315

316

317

318

319

320

321

322

323

324

325

326

327

328

329

330

331

332

333

334

335

336

337

338

339

340

341

342

343

344

345

346

347

348

349

lower than survivorship of older adults but is difficult to estimate due to low natal fidelity in most landbird species (Hobson, Wasenaar \& Bayne, 2004; Anders \& Marshall, 2005; Cooper, Daniels \& Walters, 2008; Faaborg et al., 2010). In any case, presuming that yearlings show lower reproductive success than older birds, our results indicate that habitats with high yearling proportions could be located within sink as opposed to source habitats.

\section{Conclusions}

To our knowledge, this study represents the first attempt to model the probability of capturing yearling landbirds against habitat factors using a multi-species approach. For many landbird species, age can only be accurately determined in the hand, so our dataset provides the only large-scale, long-term data set that we are aware of that permits estimation of yearling agestructure of both sexes combined. Key to deriving accurate yearling proportions is observer training in age-determination criteria and validation through a procedure like the photographic review and aging confirmation processes used here.

Our results suggest that yearling landbirds are excluded from optimal breeding habitats by older adults, although they might disperse into more optimal habitats the year following breeding as yearlings. The probability of capturing a yearling of forest-dwelling species was higher in successional-stage habitats, and vice versa. In conjunction with other vital rates estimated using MAPS data (i.e., productivity, survivorship), yearling proportion may help identify sink habitats and estimate juvenile survival, on a species-by-species basis.

\section{Acknowledgements}

Funding in support of this project is provided by Syncrude Canada Ltd., Hammerstone Corporation, Canadian Natural Resources Limited, Cenovus Energy, ConocoPhillips Canada Resources Corp., Devon Energy, Husky Oil Operations Ltd., Imperial Oil Ltd., Suncor Energy Inc., TOTAL E\&P Canada, CNOOC International, and the Oil Sands Developers Group. We are greatly indebted to the many banders who helped collect data over the six-year period. P. Lai and L. Lade (OMEI) and R. Taylor, L. Helton, C. Ray, and R. Siegel (IBP) provided MAPS protocol-related expertise and program support. This is Contribution No. 590 of The Institute for Bird Populations.

\section{References}

Albert SK, DeSante DF, Kaschube DR, Saracco JF. 2016. MAPS (Monitoring Avian Productivity and Survivorship) data provide inferences on demographic drivers of population trends for 158 species of North American landbirds. North American Bird Bander 41:133140

Anders AD, Marshall MR. 2005. Increasing the accuracy of productivity and survival estimates in assessing landbird population status. Conservation Biology 19:66-74.

Barber CA, Robertson RJ. 1999. Floater males engage in extrapair copulations with resident female tree swallows. The Auk 116:264-269.

Bartels SF, Chen, HYH, Wulder MA, White JC. 2016. Trends in post-disturbance recovery rates of Canada's forests following wildfire and harvest. Forest Ecology and Management 361:194-207 
350

351

352

353

354

355

356

357

358

359

360

361

362

363

364

365

366

367

368

369

370

371

372

373

374

375

376

377

378

379

380

381

382

383

384

385

386

387

388

389

390

391

392

Bayne EM, Hobson KA. 2001. Effects of habitat fragmentation on pairing success of Ovenbirds: importance of male age and floater behavior. The Auk 118:380-388.

Cooper CB, Daniels SJ, Walters JR. 2008. Can we improve estimates of juvenile dispersal distance and survival? Ecology 89:3349-3361.

DeSante DF. 1995. Suggestions for future directions for studies of marked migratory landbirds from the perspective of a practitioner in population management and conservation. Journal of Applied Statistics 22:949-965.

DeSante DF, Kaschube DR. 2009. The Monitoring Avian Productivity and Survivorship (MAPS) Program 2004, 2005, and 2006 report. Bird Populations 9:86-169.

DeSante DF, Nott MP, O'Grady DR. 2001. Identifying the proximate demographic cause(s) of population change by modeling spatial variation in productivity, survivorship, and population trends. Ardea 89(special issue):185-207.

Donovan TM, Thompson FR III, Faaborg J, Probst JR. 1995. Reproductive success of migratory birds in habitat sources and sinks. Conservation Biology 9:1380-1395.

Faaborg J, Holmes RT, Anders AD, Bildstein KL, Dugger KM, Gauthreaux SA Jr, Heglund P, Hobson KA, Jahn AE, Johnson DH, Latta SC, Levey DL, Marra PP, Merkord CL, Nol E, Rothstein SI, Sherry TW, Sillett TS, Thompson FR III, Warnock N. 2010. Recent advances in understanding migration systems of New World land birds. Ecological Monographs 80:3-48.

Foster KR, Godwin CM, Pyle P, Saracco J. 2017. Reclamation and habitat-disturbance effects on landbird abundance and productivity indices in the oil sands region of northeastern Alberta, Canada. Restoration Ecology DOI 10.1111/rec.12478.

Glenn EP, Huete AR, Nagler PL, Nelson SG. 2008. Relationship between remotely-sensed vegetation indices, canopy attributes and plant physiological processes: what vegetation indices can and cannot tell us about the landscape. Multidisciplinary Digital Publishing Institute DOI 10.3390/s8042136.

Graves GR. 1997. Geographic clines in age ratios of Black-throated Blue Warblers (Dendroica caerulescens). Ecology 78:2524-2531.

Greenwood PJ, Harvey PH. 1982. The natal and breeding dispersal of birds. Annual Review of Ecological Systems 13:1-21.

Haché S, Villard M.-A. 2010. Age-specific response of a migratory bird to an experimental alteration of its habitat. Journal of Animal Ecology 79:897-905.

Hobson KA, Wassenaar LI, Bayne E. 2004. Using isotopic variance to detect long-distance dispersal and philopatry in birds: an example with Ovenbirds and American Redstarts. Condor 106:732-743.

Holmes RT, Marra PP, Sherry TW. 1996. Habitat-specific demography of breeding Blackthroated Blue Warblers (Dendroica caerulescens): implications for population dynamics. Journal of Animal Ecology 65:183-195.

Hunt PD. 1996. Habitat selection by American Redstarts along a successional gradient in northern hardwoods forest: evaluation of habitat quality. Auk 113:875-888.

Jenni L, Winkler R. 1994. Moult and ageing of European passerines. London: Academic Press. Kellner K. 2015. jagsUI: a wrapper around "rjags" to streamline "JAGS" analyses. R package 1.3.7. http://CRAN.R-project.org/package=jagsUI.

Peer] reviewing PDF | (2019:09:41351:1:1:NEW 31 Jan 2020) 
393

394

395

396

397

398

399

400

401

402

403

404

405

406

407

408

409

410

411

412

413

414

415

416

417

418

419

420

421

422

423

424

425

426

427

428

429

430

431

432

433

434

Ligges U, Mächler M. 2003. Scatterplot3d - an R Package for visualizing multivariate data. Journal of Statistical Softwear 8:1-20.

Newton I. 2004. Population limitation in migrants. Ibis 146:97-226.

Plummer, M. 2003. JAGS: a program for analysis of Bayesian graphical models using Gibbs sampling. Proceedings of the 3rd International Workshop on Distribution and Statistical Computing, Vienna. https://www.r-project.org/conferences/DSC2003/Proceedings/Plummer.pdf.

Pulliam HR. 1995.Sources, sinks, and population regulation. American Naturalist132:652-661.

Pyle P. 1997. Identification guide to North American birds, part I. Bolinas: Slate Creek Press.

R Core Team. 2015. R: A language and environment for statistical computing (R Foundation for Statistical Computing. https://www.r-project.org/foundation/.

Robinson RA, Julliard R, Saracco JF. 2009. Constant effort: studying avian population processes using standardised ringing. Ringing \& Migration 24:199-204.

Rodenhouse N, Sherry TW, Holmes RT. 1997. Site-dependent regulation of population size: a new synthesis. Ecology 78:2025-2042.

Rodewald, P. (Editor). 2015. The Birds of North America: https://birdsna.org. Cornell Laboratory of Ornithology, Ithaca, NY.

Rohwer SA. 2004. Using age ratios to infer survival and despotic breeding dispersal in hybridizing warblers. Ecology 85:423-431.

Rushing CS, Ryder TB, Scarpignato AL, Saracco JF, Marra PP. 2015. Using demographic attributes from long-term monitoring data to delineate population structure. Journal of Applied EcologyDOI 10.1111/1365-2664.12579.

Ryu HY, Shoemaker KT, Kneip E, Pidgeon A, Heglund P, Bateman B, Thogmartin W, Akçakaya HR. 2016. Developing population models with data from marked individuals. Biological Conservation 197:190-199.

Saracco JF, DeSante DF, Kaschube DR. 2008. Assessing landbird monitoring programs and demographic causes of population trends. Journal of Wildlife Management 72:1665-1673.

Saracco JF, Radley P, Pyle P, Rowan E, Taylor R, Helton L. 2016. Linking vital rates of landbirds on a tropical island to rainfall and vegetation greenness. PLOS ONE11(2): e0148570 DOI 10.1371/journal.pone.0148570

Saracco JF, Fettig SM, San Miguel GL, MehIman DW, Thompson BE, Albert SK. 2018. Avian demographic responses to drought and fire: a community-level perspective. Ecological Applications DOI:10.1002/eap.1751.

Sherry TW, Holmes RT. 1989. Age-specific social dominance affects habitat use by breeding American Redstarts (Setophaga ruticilla): a removal experiment. Behavioral Ecology and Sociobiology 25:327-333.

Sillett TS, Holmes RT. 2005. Long-term demographic trends, limiting factors, and the strength of density dependence in a breeding population of a migratory songbird. In: Greenberg R, Marra PP, eds. Birds of two worlds: the ecology and evolution of migration. Baltimore: Johns Hopkins University Press.

Sillett TS, Holmes RT, Sherry TW. 2000.Impacts of a global climate cycle on population dynamics of a migratory songbird. Science 288:2040-2042. 
435 Tuck SL, Phiilips HR, Hintzen RE, Scharlemann JP, Purvis A, Hudson LN. 2014.

436 MODISTools - downloading and processing MODIS remotely sensed data in R. Ecology and $437 \quad$ Evolution 4:4658-4668.

438 


\section{Table $\mathbf{1}$ (on next page)}

Table 1 for Yearling proportion correlates with habitat structure in a Boreal forest landbird community.

Table 1. Sample summaries, age error rates, and yearling proportions for landbird species captured in the boreal forest of northeastern Alberta. Four-letter alpha codes presented here are used in Figures 4 and 5. Number of stations in which the species was captured is indicated (Stas.) Year-unique individuals (Year-Inds.) indicate the summed number of individuals captured per year (including between-year recaptures). Numbers of yearling adults (SY), older adults (ASY), and adults undetermined to age (AHY) are given for each species. Age error rates were calculated as the proportion of instances an age determination of SY or ASY was changed for recapture records, as verified by recapture data, among the given sample. Yearling proportion calculated as SY/(SY+ASY). 
1 Yearling proportion correlates with habitat structure in a Boreal forest landbird community

3 Table 1.

\begin{tabular}{|c|c|c|c|c|c|c|c|c|c|}
\hline Common name & Scientific name & Code & Stas. & $\begin{array}{l}\text { Year- } \\
\text { Inds. }\end{array}$ & SY & ASY & AHY & $\begin{array}{c}\text { Age error } \\
\text { rate }(n)\end{array}$ & $\begin{array}{c}\text { Yearling } \\
\text { prop. }\end{array}$ \\
\hline Yellow-bellied sapsucker & Sphyrapicus varius & YBSA & 33 & 267 & 132 & 120 & 15 & $0.056(178)$ & 0.524 \\
\hline Alder flycatcher & Empidonax alnorum & ALFL & 36 & 845 & 166 & 573 & 106 & $0.119(345)$ & 0.225 \\
\hline Least flycatcher & Empidonax minimus & LEFL & 35 & 517 & 209 & 252 & 56 & $0.086(163)$ & 0.453 \\
\hline Red-eyed vireo & Vireo olivaceus & REVI & 31 & 507 & 78 & 360 & 69 & $0.042(143)$ & 0.178 \\
\hline Black-capped chickadee & Poecile atricapillus & $\mathrm{BCCH}$ & 29 & 190 & 48 & 62 & 80 & $0.071(99)$ & 0.436 \\
\hline Ruby-crowned kinglet & Regulus calendula & RCKI & 18 & 155 & 48 & 62 & 45 & $0.021(47)$ & 0.436 \\
\hline Swainson's thrush & Catharus ustulatus & SWTH & 36 & 747 & 276 & 356 & 115 & $0.046(263)$ & 0.437 \\
\hline American robin & Turdus migratorius & AMRO & 35 & 471 & 204 & 210 & 57 & $0.132(151)$ & 0.493 \\
\hline Cedar waxwing & Bombycilla cedrorum & CEDW & 27 & 358 & 142 & 191 & 25 & $0.017(60)$ & 0.426 \\
\hline Chipping sparrow & Spizella passerina & $\mathrm{CHSP}$ & 38 & 801 & 302 & 427 & 72 & $0.080(224)$ & 0.414 \\
\hline Clay-colored sparrow & Spizella pallida & CCSP & 23 & 755 & 299 & 399 & 57 & $0.128(344)$ & 0.428 \\
\hline Savannah sparrow & Passerculus sandwichensis & SAVS & 5 & 266 & 71 & 179 & 16 & $0.140(136)$ & 0.284 \\
\hline Song sparrow & Melospiza melodia & SOSP & 15 & 141 & 39 & 88 & 14 & $0.134(97)$ & 0.307 \\
\hline Lincoln's sparrow & Melospiza lincolnii & LISP & 35 & 546 & 203 & 277 & 66 & $0.180(417)$ & 0.423 \\
\hline Swamp sparrow & Melospiza georgiana & SWSP & 23 & 216 & 119 & 75 & 22 & $0.088(159)$ & 0.613 \\
\hline White-throated sparrow & Zonotrichia albicollis & WTSP & 37 & 1474 & 450 & 853 & 171 & 0.089 (1093) & 0.345 \\
\hline Ovenbird & Seiurus aurocapilla & OVEN & 37 & 567 & 212 & 278 & 77 & $0.084(178)$ & 0.433 \\
\hline
\end{tabular}




\begin{tabular}{|l|l|c|c|c|c|c|c|c|c|}
\hline Northern waterthrush & Parkesia noveboracensis & NOWA & 19 & 127 & 19 & 88 & 20 & $0.061(66)$ & 0.178 \\
\hline Black-and-white warbler & Mniotilta varia & BAWW & 30 & 261 & 117 & 113 & 31 & $0.026(77)$ & 0.509 \\
\hline Tennessee warbler & Oreothlypis peregrina & TEWA & 37 & 2399 & 968 & 1148 & 283 & $0.055(660)$ & 0.457 \\
\hline Mourning warbler & Geothlypis philadelphia & MOWA & 20 & 220 & 73 & 130 & 17 & $0.077(195)$ & 0.360 \\
\hline Common yellowthroat & Geothlypis trichas & COYE & 28 & 236 & 67 & 145 & 24 & $0.081(111)$ & 0.316 \\
\hline American redstart & Setophaga ruticilla & AMRE & 22 & 214 & 85 & 106 & 23 & $0.049(81)$ & 0.445 \\
\hline Magnolia warbler & Setophaga magnolia & MAWA & 27 & 292 & 143 & 133 & 16 & $0.073(219)$ & 0.518 \\
\hline Yellow warbler & Setophaga petechia & YEWA & 21 & 309 & 106 & 167 & 36 & $0.041(197)$ & 0.388 \\
\hline Yellow-rumped warbler & Setophaga coronata & YRWA & 29 & 278 & 124 & 137 & 17 & $0.194(93)$ & 0.475 \\
\hline Canada warbler & Cardellina canadensis & CAWA & 22 & 304 & 129 & 121 & 54 & $0.133(165)$ & 0.516 \\
\hline Wilson's warbler & Cardellina pusilla & WIWA & 28 & 193 & 70 & 93 & 30 & $0.132(91)$ & 0.429 \\
\hline Rose-breasted grosbeak & Pheucticus ludovicianus & RBGR & 22 & 134 & 44 & 81 & 9 & $0.000(33)$ & 0.352 \\
\hline
\end{tabular}

4

5 Table 1. Sample summaries, age error rates, and yearling proportions for landbird species captured in the boreal forest of northeastern

6 Alberta. Four-letter alpha codes presented here are used in Figures 4 and 5. Number of stations in which the species was captured is

7 indicated (Stas.) Year-unique individuals (Year-Inds.) indicate the summed number of individuals captured per year (including between-

8 year recaptures). Numbers of yearling adults (SY), older adults (ASY), and adults undetermined to age (AHY) are given for each

9 species. Age error rates were calculated as the proportion of instances an age determination of SY or ASY was changed for recapture

10 records, as verified by recapture data, among the given sample. Yearling proportion calculated as SY/(SY+ASY). 


\section{Figure 1}

Study region.

(A) Study region within Alberta, Canada. (B) MAPS station locations; stations comprised largely $(>90 \%)$ of natural boreal habitats $(n=15)$ are indicated with green triangles, those affected by disturbance from resource development activities ( $n=15 ; 0-89 \%$ natural habitats) with open orange squares, and stations in reclaimed sites $(n=5)$ are indicated with open yellow circles. (C) Surrounding habitats for five reclaimed stations, with color coding corresponding to that in Fig. 2; see Foster et al. (2017) for station codes. Map data for B: Stamen Design, under CC BY 3.0. Data by OpenStreetMap, under ODbL; Map data for C: Google, TerraMetrics). 

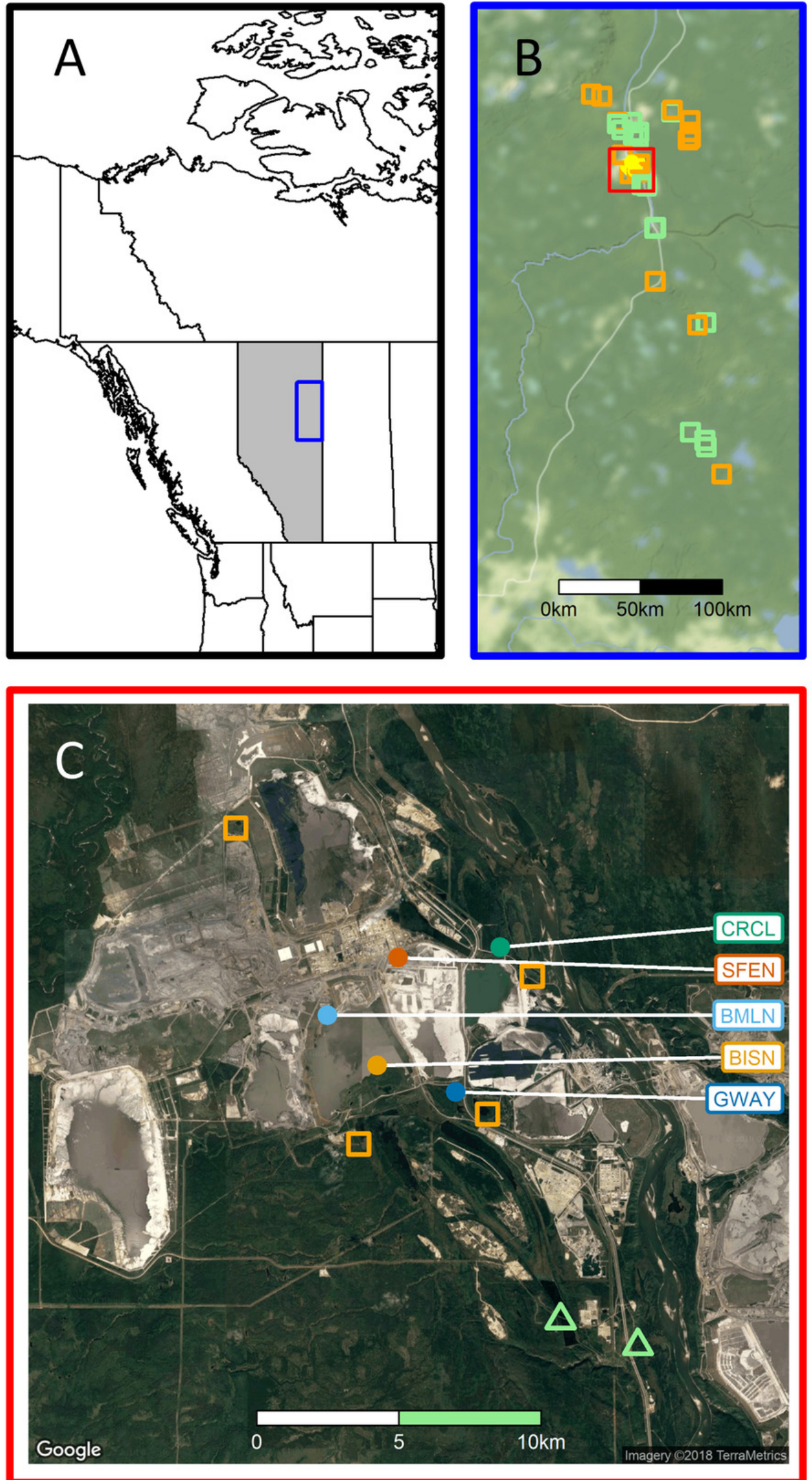

Peer) reviewing PDF | (2019:09:41351:1:1:NEW 31 Jan 2020) 


\section{Figure 2}

Relationships between habitat variables and years since initiation of reclamation at 15 MAPS stations dominated by natural vegetation and five stations with predominantly reclaimed habitat.

Colors denote individual reclaimed stations (see Fig. 1). Natural sites (those with $>90 \%$ natural boreal habitats; $n=15$ ) are aggregated into boxplot to right. (A-C) Points represent values from in-situ habitat assessments in 2013. (D) Points represent June Enhanced Vegetation Index (EVI) values from up to 16 years per station (among years 2000-2015). Note that both understory and upperstory cover showed little correlation with years since reclamation whereas mid-story cover showed substantial increases, approaching those of natural sites by 30 years post reclamation. EVI values appear to reflect mid-story development, equating with natural stations at 15-20 years post reclamation. 

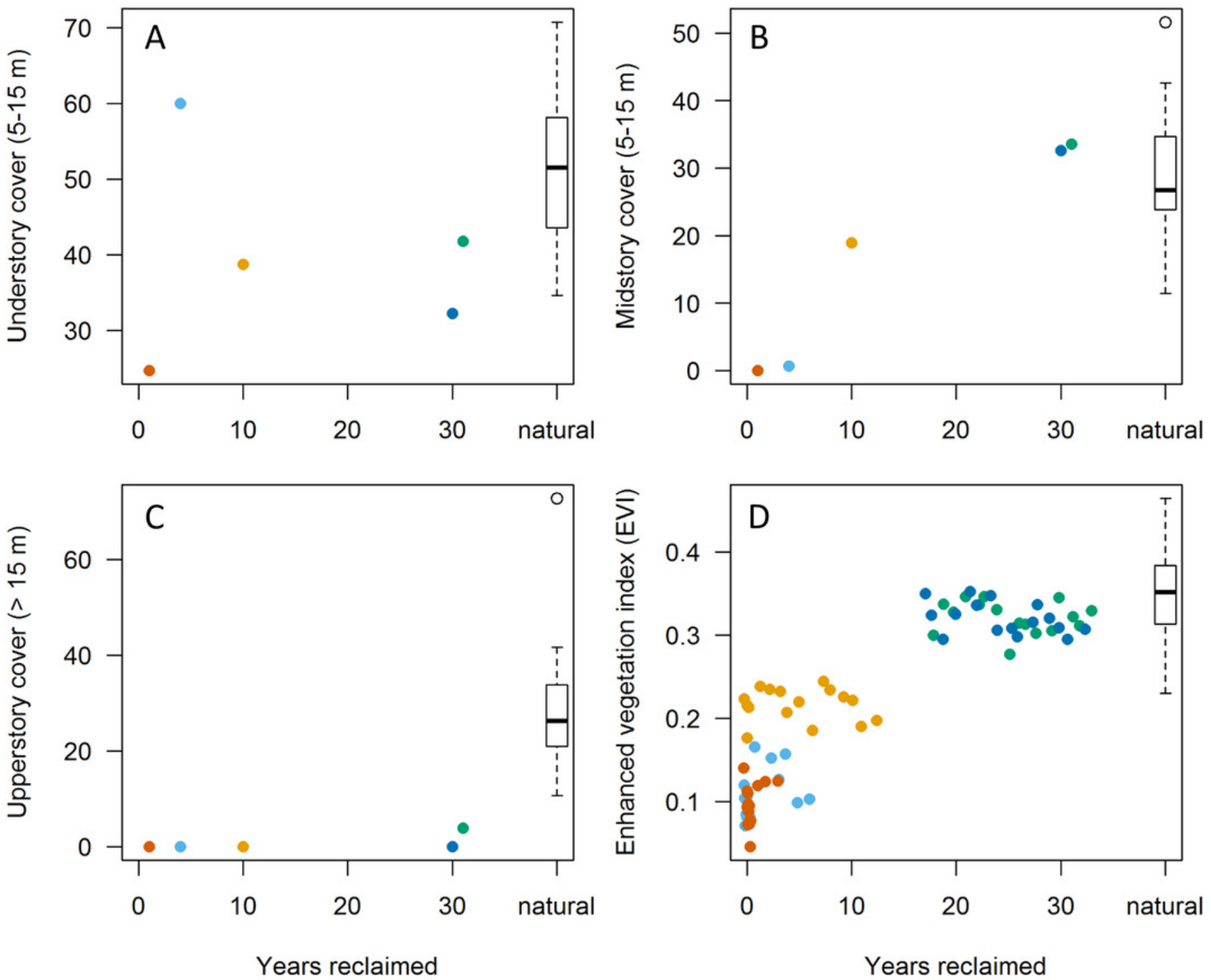


\section{Figure 3}

Three-dimensional scatterplot indicating that Enhanced Vegetation Index (EVI) increases with \% natural vegetation and years since habitat reclamation commenced.

The dashed plane shows the bivariate linear regression fit $\left(R^{2}=0.35\right)$. Standardized regression coefficient for \% natural was $0.064(95 \% \mathrm{Cl}: 055,0.074)$ and for years reclaimed was $0.030(0.021,0.040)$. Colors distinguish individual stations (see Figs. 1 and 2); other colors represent the 15 stations affected by disturbance from resource development activities, ranging from $0 \%$ to $89 \%$ of the station estimated to be in natural habitats (Foster et al., 2017). 


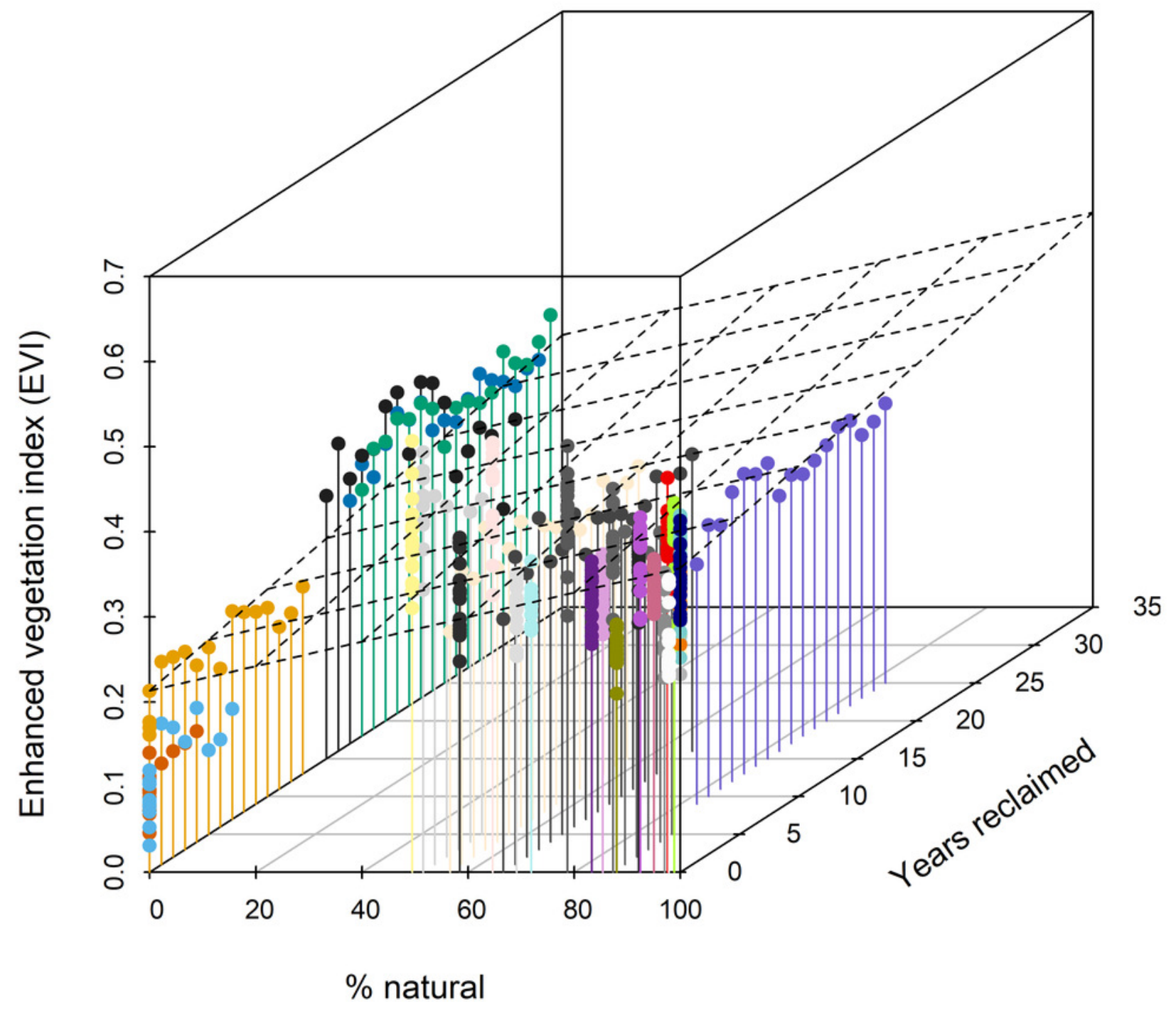




\section{Figure 4}

Results of multispecies hierarchical model to investigate the relationship between the age structure of adult birds and Enhanced Vegetation Index (EVI).

Mean estimates for species in which adults were captured at highest rates in successional (tan; lowest EVI quartile), intermediate (light green; middle two EVI quartiles), and mature forest (dark green; upper EVI quartile) habitats, as measured by our in-situ habitat structure data, are shown to highlight potential habitat-related differences in yearling responses. (A) Estimated mean yearling probability (black line) $\pm 95 \%$ cred. int. (gray polygon) across observed range of EVI values ( $\mu_{\beta}=-1.29 ; 95 \%$ cred. int.: $\left.-2.49,-0.18\right)$. (B) EVI coefficient estimates ( $\pm 95 \%$ cred. int.) for each of the 29 target species, sorted from most negative (top) to most positive (bottom) EVI coefficient; species codes are defined in Table 1. The estimated mean species-EVI effect is indicated by a dashed line and gray region delineates the $95 \%$ credible region. (C) Box plots show distribution of mean coefficients for the 3 species groupings. The mean EVI coefficient for species with EVI values in the lowest quartile across species was -0.55 (95\% conf. int: $-3.64,3.67)$, that for species in the middle half was -1.38 (95\% conf. int: $-5.60,2.88$ ), and that for species in the highest quartile -1.95 (95\% conf. int: $-6.72,1.83)$. This indicates that yearling proportions for forest-dwelling species are lower in more-forested (greener) habitats whereas those of successional-habitat species is higher in forested habitats. 

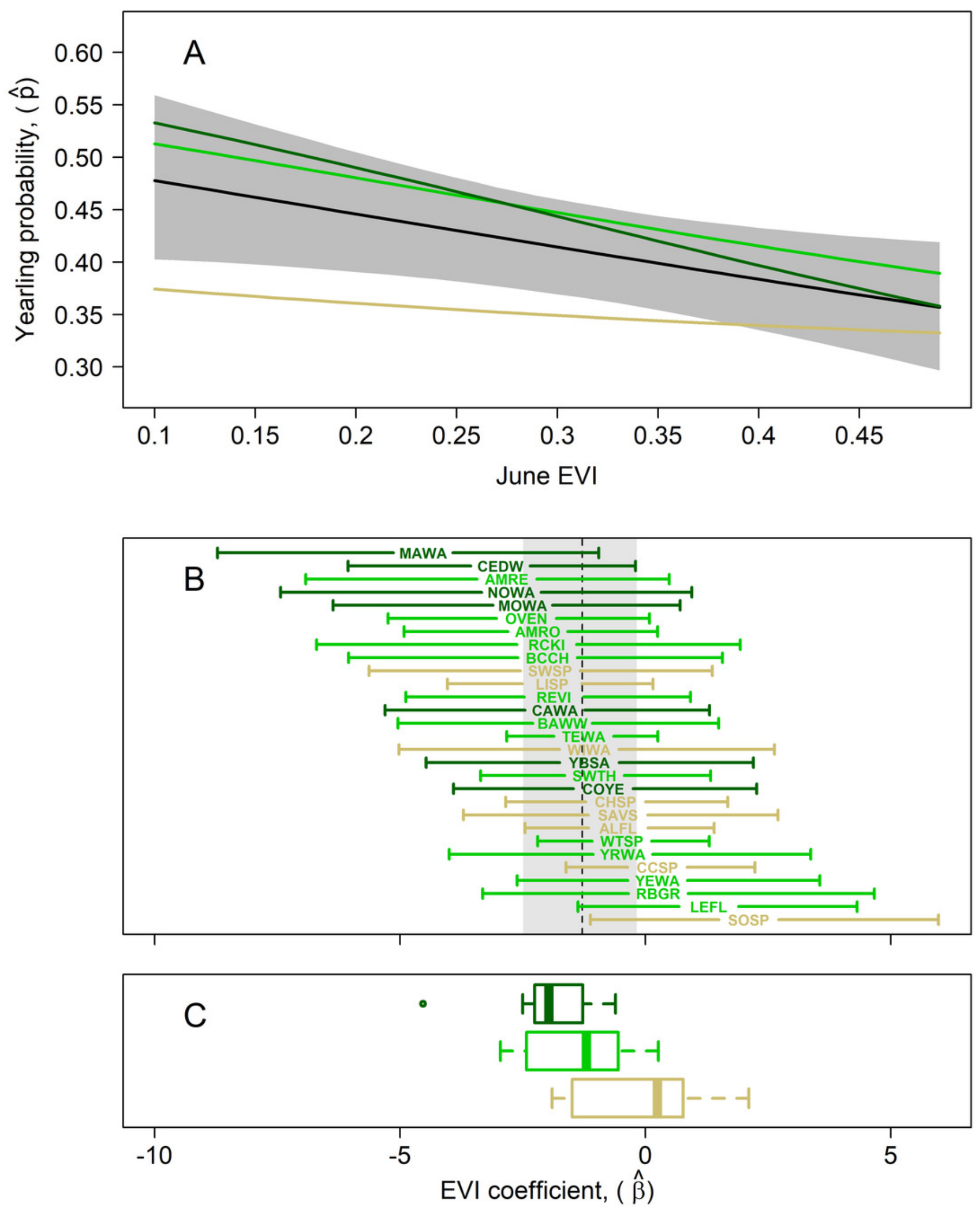


\section{Figure 5}

Relationship between species coefficients as a function of the EVI mean and EVI range observed for that species.

The plane shows the bivariate regression fit ( $\mathrm{R}$-squared $=0.28)$. This relationship is highly significant (standardized regression coefficient $=-0.717,95 \% \mathrm{Cl}:-1.206,-0.278$ ) and there was a slightly positive relationship between the EVI coefficient and the EVI range. Four-letter codes (see Table 1) for outlying species are shown; see Fig, 4 for species-habitat color representation. 


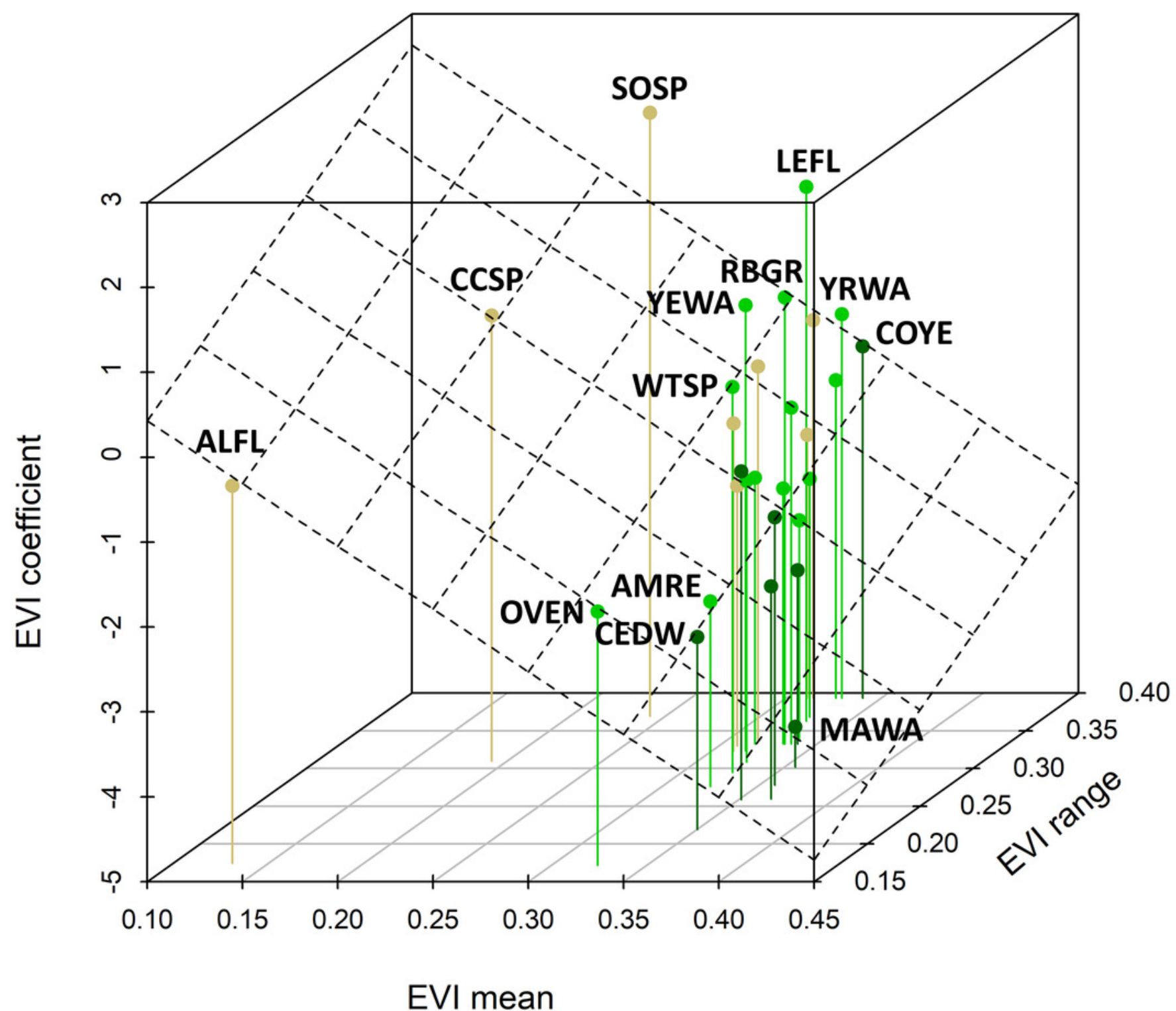

